\title{
COMBINING COLLABORATIVE USER EXPERIENCE DESIGN WITH CROWD ENGINEERING: A PROBLEM- BASED LAB COURSE FOR (UNDER-)GRADUATE STUDENTS
}

\author{
Daniel KERPEN ${ }^{1}$, Yannick JURESA ${ }^{2}$, Sven FORTE ${ }^{2}$, Jan CONRAD ${ }^{1}$, Jens C. GÖBEL ${ }^{2}$ \\ and Dieter P. WALLACH ${ }^{1}$ \\ ${ }^{1}$ Hochschule Kaiserslautern - University of Applied Sciences, Computer Science, and \\ Microsystem Technologies, Zweibrücken, Germany \\ ${ }^{2}$ TU Kaiserslautern, Institute of Virtual Product Engineering (VPE), Kaiserslautern, Germany
}

\begin{abstract}
This paper proposes a university course centred around a problem-based laboratory called "Crowd Engineering (CE)". As a result of the COVID-19 pandemic, collaborative work had to be moved predominantly into the virtual space. Thus, the need for virtual collaborative work in teaching increased significantly. CE is a joint remote collaboration by two academic institutions working together in a transfer-oriented, publicly funded project. In the course, design and product engineering students learnt to cope with today's complex problems. They acquire skills to think beyond subject and system boundaries and are equipped with these job-related qualities already during university education by solving a crowd-sourced real-world task. Students worked with various tools to arrive at an initial design proposal that is supposed to be implemented in a future physical prototype. This paper describes the collaboration context of both university partners, concept development and implementation of the laboratory course and lessons learned from the collaboration.
\end{abstract}

Keywords: Collaborative user experience design, crowd engineering, collaborative virtual product engineering, interface design and development

\section{INTRODUCTION}

Designers and engineers must cope with adaptability by the very nature of their activities: The development of new products and services is changing rapidly, e.g., products are becoming more and more complex, digitized, and interconnected [1]. Both, designers, and engineers increasingly need to cooperate in physically distributed and cross-disciplinary teams [2]. Higher education of prospective designers and engineers must address these requirements by developing innovative course formats. Only such teaching from undergraduate level onwards prepares students adequately to meet today's complex challenges. Students need to learn how to think beyond subject silos and system boundaries already during university education, for instance by understanding potentially interdependent economic and social aspects of the respective innovation contexts. Our paper exemplifies this approach with the case study of a problem-based laboratory course called "Crowd Engineering (CE)". CE is a joint remote collaboration of the Institute for Virtual Product Engineering (VPE) at TU Kaiserslautern and HumanComputer Interaction Research Group Zweibrïcken (HCI2B) at Hochschule Kaiserslautern - University of Applied Sciences. CE addresses students from two distinctive but complementary backgrounds, in particular higher term bachelor students from the field of User Experience Design (UX) and master's students of product engineering theory. In doing so, CE pairs mechanical and systems engineering with the digital media - and information technology-heavy UX profession - eminently important for today's smart product development. Section 2 describes the context of the participating university partners and gives an outline of the related work. Section 3 focuses on the real-world task definition of designing and prototypically implementing features of a touch screen-based ordering system for meal self-service in a university canteen/cafeteria ("MENSA Live"). This overall course goal was crowd-sourced to student groups that were assigned to specific tasks. Section 4 discusses lessons learnt and provides an outlook on potential future work. 


\section{RELATED WORK AND BACKGROUND OF COURSE PARTNERS}

The term crowd engineering is borrowed from crowd sourcing: Howe [3] defines crowd sourcing as a composition of 'crowd' and 'outsourcing', i.e., the task of distributing a function previously assigned internally to employees to a heterogeneous network. In our context, crowd sourcing does not equal outsourcing a function to an undefined network, but to a network of acknowledged participants - an important practice in today's design and engineering contexts [4], [5]. The concept of crowd engineering was implemented by VPE for the first time in 2016 [1]. Based on this earlier experience of a joined engineering course with another university and a German automotive OEM, a new version of the course was launched in 2020 with HCI2B as a new partner (see Sec. 3).

We followed a seven-stage digital engineering lifecycle in our work of model-driven digital product and service engineering (Fig. 1): The outlined digital engineering lifecycle supports the transformation of traditional products and services toward networked (smart) products and innovative services as shown in Figure 1.

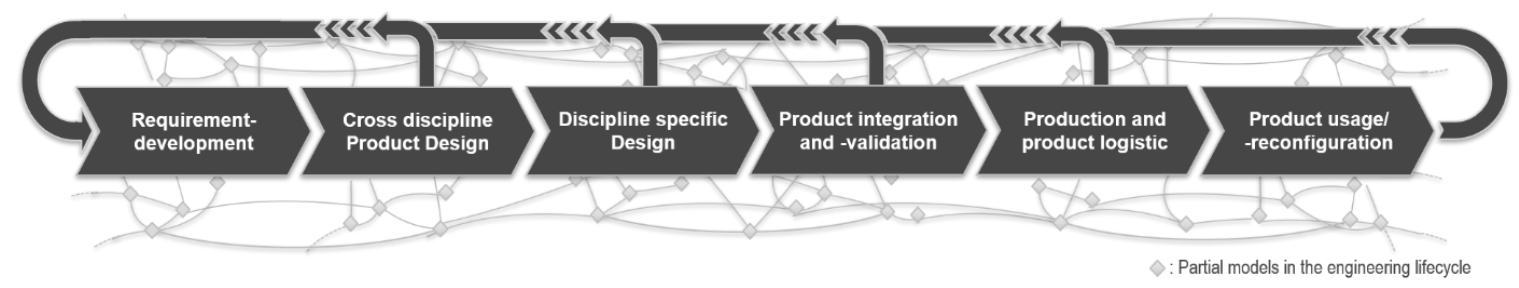

Figure 1. The Digital Engineering 4.0 Lifecyle

This concept of digital engineering lifecycle is a core concept in the works of the Institute of Virtual Product Development (VPE): The activities of the Institute of Virtual Product Development (VPE) focus on topics from Smart System Lifecycle Management and Smart Systems Engineering (e.g., ClosedLoop Systems Engineering [6]). In research and teaching, VPE deals with processes, methods, and IT tools for digital development ("Digitized Engineering") and the management of smart, networked products and product service systems (PSS). VPE uses a holistic learning concept for product engineering. The teaching offered in this area extends from the second bachelor's semester through to the master's degree. The lectures and laboratories offered thematically build on each other. Core concepts of the second partner of the lab course, HCI2B, are as follows: a focus on lightweight Usability and User Experience (UUX) methods and respective (quantitative) UUX metrics [2], [7]. This approach is tightly coupled with the dissemination of usability concepts and practices centring around Collaborative User Experience Design (CUXD) as a model for integrating lean UUX methods and disseminating them in operational processes [8]. VPE and HCI2B are partners in the interdisciplinary transfer project Open Digitalization Alliance Palatinate. In this project, a consortium of different research institutions and transfer partners joined forces to develop a culture of transfer-orientation in different innovation fields of digitalization. For instance, VPE and HCI2B investigate applications and implications of innovative methods in design and product development in industrial production engineering.

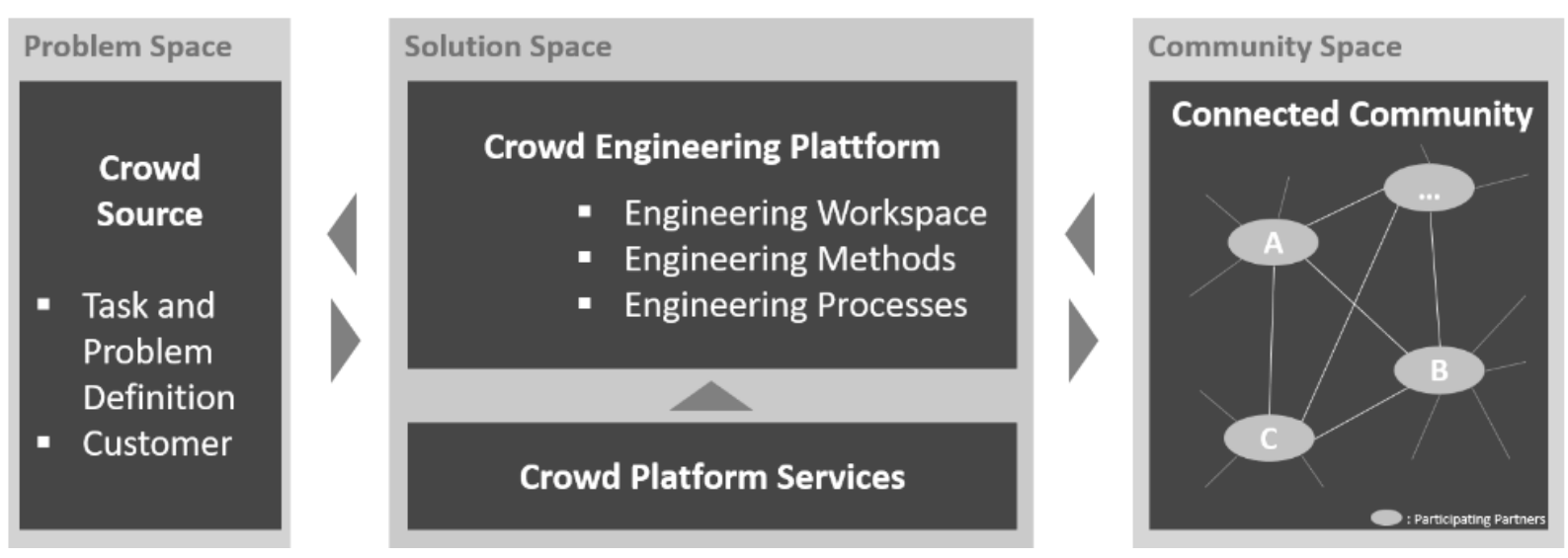

Figure 2. Crowd Engineering (CE) Lecture Framework HCI2B \& VPE 


\section{COURSE CONCEPT AND USE CASE}

The real-world task of the laboratory course focuses on the design and (partial) implementation of the automated ordering system MENSA Live. In the future, the system should enable contactless ordering in the university cafeterias. This task follows the subsequent CE lecture framework (Fig. 2 and 3): First, students need to empathize with the context that manifests our problem space. The cafeteria operator struggles with Covid-19 regulations and strives for contactless ordering and queuing minimization in the facilities. Second, to achieve this goal, students draw on methods and practices of smart digitized engineering and user experience design to tackle the solution space. Third, the tasks of designing, prototyping, and validating link students in small groups through sub-processes (community space). Overall, the students are encouraged and enabled to work collaboratively and to link knowledge and skills in an interdisciplinary way through three iteratively linked project groups: requirements development, UX and Computer-Aided Design (CAD) design and modelling.

The requirements development project group initiates the process by scoping characteristics through guided interviews with stakeholders from the university canteen operator. The analysis of the interview contents is a decisive step for creating a first specification summary that serves as a basis to support further iteration loops between the different project groups throughout the project course. This project group also takes on the overall coordinating task of inviting to necessary iteration rounds that help the students to get hands-on involvement with agile project management methods and respective software tools. Tasks of the UX project group focus on the human-centred design of interactive input/output devices (UI design and development) and their prototypical implementation. The group's work promotes the usability and positive user experience of the interface and serves as crucial input for the CAD modelling. The creation of individual components in CAD software fosters coordination and data availability to the other project groups, so that different components can be created by different participants and installed in assemblies by a group coordinator. Finally, this helps students to learn about the importance of ensuring consistent data management by supporting PLM software to ensure regular consultation and correct implementation.

The lab course enables students to work collaboratively and to link knowledge and skills in an interdisciplinary manner. Enrolled were 28 students, 16 from VPE and 12 from HCI2B. Students' work in the lab was centred around the winter term 2020-2021 in the timeframe of mid-December 2020 to early February 2021. Due to the short time span of approx. eight weeks, focus was placed on the conceptual design of the system, as a physical realization was not feasible in this time.
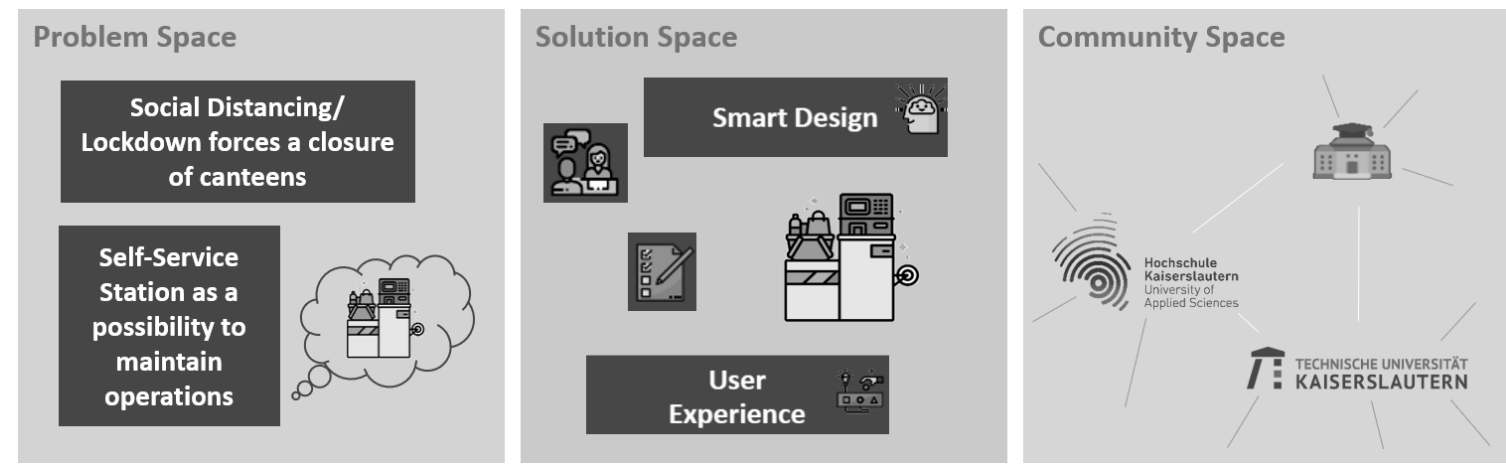

Figure 3. Actual Task in CE Lecture Framework

The approach followed lean principles [2] and was constantly accompanied by consulting and support between students, professors, and teaching staff, also during ideation and evaluation sessions. During implementation, emphasis was placed not only on content transfer but also on communication, exchange of knowledge and collaborative learning within and between the student working groups and university locations.

To summarise, the focus was set on establishing an understanding of the advantages of such an approach and the iterative stages of digitized engineering and design lifecycle in our concrete project. The project work iteratively passed through different stages: the definition of strategic aspects, the first creative prototyping approaches, design ideas, lean implementation, and iterative evaluation of the product (up to roll-out). The findings from the student project (Fig. 4) were documented and processed in such a way that a successful knowledge transfer can take place for subsequent student seminar groups and lab courses. 


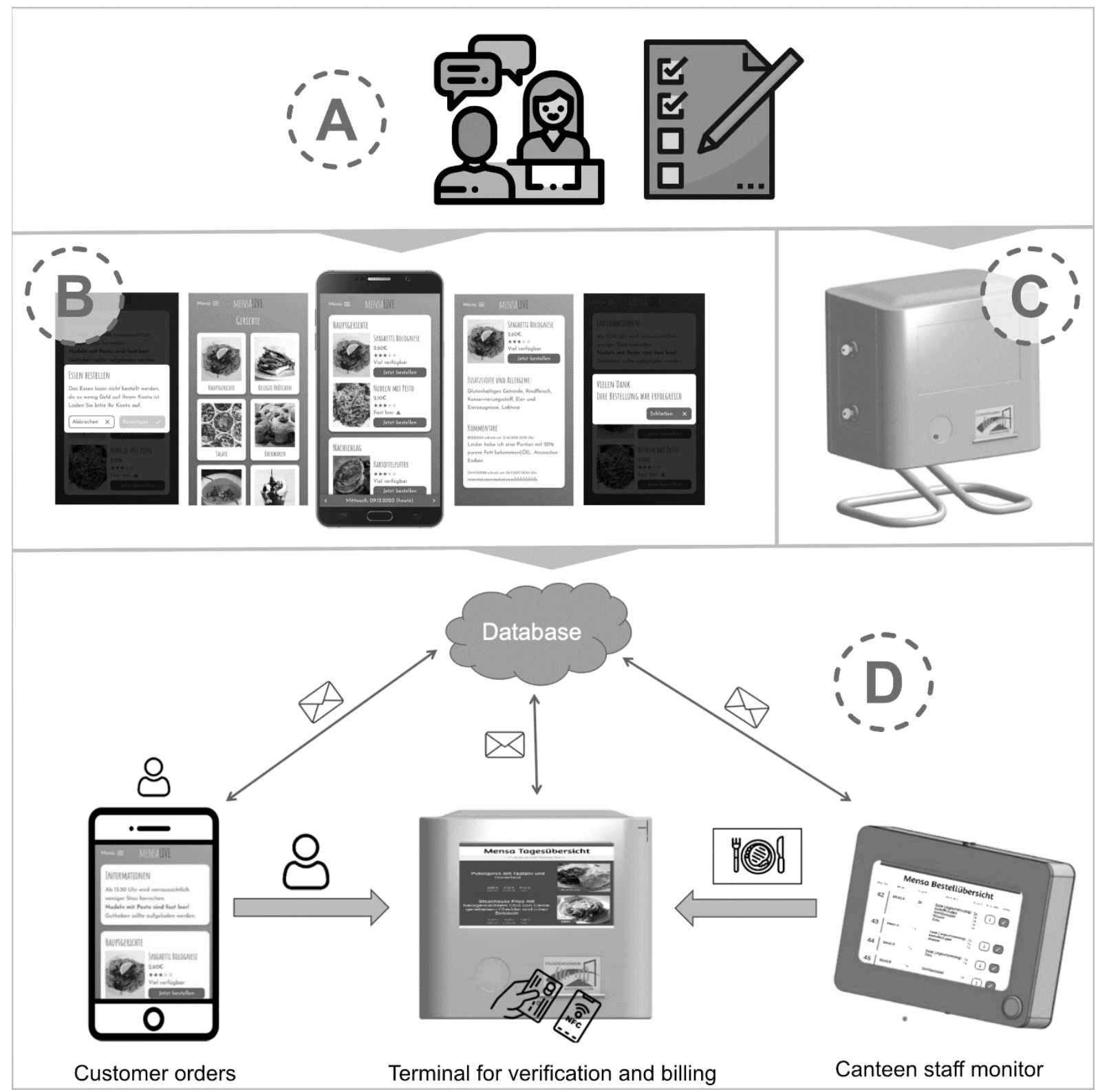

Figure 4. CE Result: MENSA Live System

(A) Stakeholder Review and Requirement Refining

(B) UI/UX Design of the Men's Alive Application

(C) MENSA Live Hardware Design (e.g., CAD)

(D) MENSA Live System Overview

The implementation of crowd engineering depends on the right choice of tools. An important factor in the implementation is the access to new information and communication technologies that have changed higher education in recent years [9]. The outsourcing of functions to a crowd is only possible through collaboratively usable tools for communication, requirements creation or design. To provide students with suitable collaborative tools, different platforms for different tasks were provided. As a general collaborative platform for data exchange and communication, teaching staff created a course on the Online Learning and Training (OLAT) [10] platform. OLAT is a web application providing closed rooms for collaborative work while integrating additional tools that include web conferencing systems. Using OLAT, course materials were made available to all students. At the same time, interim results in file format were shared in OLAT and discussed with supervisors. To give all students access to CAD software and, at the same time, to promote collaborative work on a model, the software must be accessible by different user systems. In addition, distributed work must be possible, as in a PLM system. Therefore, a cloud-based solution was preferred as CAD tool to combine both requirements. Thus, PTC Onshape [11] was made available as a student tool. In Onshape, it is possible to work on CAD models simultaneously in a browser-based manner. 
Design work followed the collaborative UX design approach and made use of prototyping tools such as Figma, Axure and Adobe XD. To implement programming, a small group of two students with extensive programming experience was split off from the other groups. In this group, software requirements were created to map the ordering process and to create a smartphone connection. A low-code-based development platform was made available as a tool. Due to the relatively short development time of only four weeks, an easy familiarization with the development environment was crucial. The low-code platform Siemens Mendix [12] allowed to create applications on a relatively intuitive and simple basis. For (mobile-first) web application development, the current Angular (version 10/11, [13]) and Bootstrap [14] frameworks were used.

The course was completed with a group-based written performance on the one hand and a presentation on the other. The written work was submitted in folders containing, e.g., a morphological box, a list of requirements, problem statement and customer journey maps, a black box, a hierarchical functional structure, price lists of purchased parts, labour hours, operating instructions, a parts list as well as technical drawings and "design the box" marketing conceptualizations. The aim of the presentation was to explain the product to the customer and thus also to promote and market the product directly.

\section{LESSONS LEARNED}

At the end of semester, the laboratory course was evaluated using a questionnaire that reviewed students' experiences and impressions by 25 items with five-level bipolar scaling (from strongly disagree to strongly agree). Questionnaire items were divided into three parts: Teamwork, task/objective/time allocation and personal experiences. Overall response rate was $78 \%$ completely answered questionnaires. Since the project partners VPE and HCI2B want to hold the course again in next year's winter term, this form of evaluation is important to gain legitimacy from the students' side. Overall, the students' impressions can be summarized as very positive with some hints for further improvement: All students were very open to an inter-university event with potential transfer partners (such as service/industry domains) and would like to see more formats following this direction.

Teamwork was perceived as somewhat difficult. Slight deficits in the formation of competencies in the individual groups were identified. Due to the different disciplines of the students, there were many sources of competencies and formal as well as informal knowledge to rely on. But active transfer of such knowledge and competencies within community spaces is not a self-establishing and selfreinforcing process. According to our current experience, it needs external triggers that were stimulated by teaching staff via direct feedback and through the collaboration tools described above. Other feedback was linked to the way in which teams worked together. Although the communication tools provided by the university were used, information was not always shared as fast and comprehensive as it was required. The performance of the respective student team leaders, who interacted not only within but also between the groups, was highlighted as very positive. The time frame of approx. eight weeks for task completion was generally considered to be sufficient.

\section{CONCLUSION AND OUTLOOK}

To summarise, students' assessment of the project was positive. The approach in its present form has not only confirmed its relevance - regarding restrictions in the Corona crisis — but has also provided an outlook on possible perspectives of expanded forms of teaching and working in the future. This next crowd engineering course will again be a joint project between VPE and HCI2B and an industrial partner. The limitations of the teaching concept outlined in Sec. 4 will be addressed. Our goal is to achieve a long-term cooperation between the teaching institutions and to keep this unique perspective attractive for subsequent students. In future courses, an even closer collaboration of students from both universities will be attempted. To this end, a task will be created by an industrial partner which conveys a high industrial value. The tools used so far require only minor adjustments, since the weaknesses that have occurred are not due to the use of the respective tools. Overall, formats such as crowd engineering show possibilities for enabling collaborative work, especially in times of difficult physical presence. For this reason, this format will continue to be part of the lecture concept of the two respective educational institutes and will be further developed and implemented in the subsequent semesters. 


\section{ACKNOWLEDGEMENTS}

We gratefully acknowledge funding from the German Federal Ministry of Education and Research (BMBF) within the German Joint Science Conference framework under grant titles 03IHS075A\&B.

\section{REFERENCES}

[1] Eigner M., Eiden A. and Apostolov H. (2017): Crowd Engineering - Bringing Full Cloud CAD into the Lab, International Conference on Engineering and Product Design Education 7.-8. September 2017, Oslo and Akershus University College of Applied Sciences, Norway, 2017, S. 5, https://www.hanser-elibrary.com/doi/10.3139/104.112226

[2] Steimle T. and Wallach D. (2018): Collaborative UX Design, dpunkt Verlag, Heidelberg, 2018, ISBN 978-3-96088-283-1

[3] Howe J. (2006): The Rise of Crowdsourcing, Wired Magazine, 2006, 14, 176-183.

[4] Hirth M., Hoßfeld T., Mellia M., Schwartz C., and Lehrieder F. (2015): Crowdsourced network measurements: Benefits and best practices, Computer Networks, Volume 90, 2015, Pages 85-98, ISSN 1389-1286, https://doi.org/10.1016/j.comnet.2015.07.003

[5] Kietzmann J. H. (2017): Crowdsourcing: A revised definition and introduction to new research, Business Horizons, Volume 60, Issue 2, 2017, Pages 151-153, ISSN 0007-6813, https://doi.org/10.1016/j.bushor.2016.10.001

[6] Dickopf T., Forte S., Apostolov C., and Göbel J. C. (2021): Closed-Loop Systems Engineering How MBSE and IoT together support system improvement!, CSD\&M Asia 2020, 2021 (to be published).

[7] Wallach D., Conrad, J., and Steimle T. (2017): The UX metrics table: a missing artifact, In A. Marcus \& W. Wang (eds.), Design, User Experience, and Usability: Theory, Methodology, and Management, 2017, Springer, Cham, 507-517. https://doi.org/10.1007/978-3-319-58634-2_3

[8] Kerpen D., Conrad J., and Wallach D. (2020): A Formalisation Approach for Collaborative User Experience Design, Proceedings of the Design Society: DESIGN Conference 2020, Cambridge University Press, 947-956. https://doi.org/10.1017/dsd.2020.312

[9] Pucciarelli F. and Kaplan A. (2016): Competition and strategy in higher education: Managing complexity and uncertainty, Business Horizons, 59(3), 311-320.

[10] OLAT 2021: OpenOlat - infinite learning Platform, https://olat.vcrp.de/dmz/ [Accessed on 2021, $05 \mathrm{March}]$.

[11] Onshape 2021: Complete All-In-One Product Development Platform | Onshape, https://www.onshape.com/en/platform [Accessed on 2021, 05 March].

[12] Mendix 2021: Mendix Low-Code Platform Features - Low-Code App Development Tools, https://www.mendix.com/platform/

[13] Google (2020): Angular web developer's platform, https://angular.io/ [Accessed on 2021, 05 March].

[14] Bootstrap (2020): Bootstrap front-end open-source toolkit, https://getbootstrap.com/ [Accessed on 2021, 05 March]. 